\title{
EVALUATION OF SIDA ACUTA SUBSPECIE ACUTA LEAF/FLOWER COMBINATION FOR ANTIMICROBIAL ACTIVITY AND PHYTOCHEMICAL CONSTITUENTS
}

-

SAGANUWAN, ALHAJI SAGANUWAN \& GULUMBE, MOHAMMED LAWAL.

Department Of Veterinary. Physiology, Pharmacology And Biochemistry, College Of Veterinary Medicine, University Of Agriculture P.M.B 2373, Makurdi, Benue State, \& Depłrtment Of Veterinary Public Health And Animal Production , Faculty Of Veterinary Medicine , Usmanu Danfodiyo University, P.M.B 2346, Sokoto , Sokoto State - Nigeria .

\section{Correspondence to: Saganuwan, A.S.}

\section{ABSTRACT}

Sida acuta subspecie acuta leat/flower combination was evaluated for antimicrobial activity and phytochemical constituents using methanol, hexane, chloroform and aqueous method of extractions. The antibacterial activities were exhibited by the four extracts on $E$. coli, $S$. pyogenes, $P$. multocida and $S$. typhumurium as there was no activity exhibited on $S$. tyhi, S. pneumoniae and $\boldsymbol{K}$. phneumoniae., Phytochemical analyses revealed the presence of alkaloid, tannin, flavonoid and saponin whereas steroid and glycoside were absent.

Key words: Evaluation, Sida, acuta, leaf, nower, antimicrabial, phytochemical, constituents.

\section{INTRODUCTION}

Sida acuta subspecie acula(Hom-beam-leaved sida,) is herb of about $0.7 \mathrm{~m}$ high with numerous erect branches, the leaves are oval, dentate. about $6.5-7.5 \mathrm{~cm}$ long and $1-2 \mathrm{~cm}$ broad (1). Inflorescence consists of flowers that are solitary, axillary and sometimes with terminal pauciflorous glomerule, although, fruits are more or less globular and covered on top with golden hairs as inside the fruit is ovoid containing black numerous seeds (1). Pan tropical wild species, grow around roadside, and on waste land medicinally used for malaria, gonorrhoea, abortion, breast cancer (1), inflammation and poisoning (2). Phytochemically, Sida acuta subspecie acuta contains saponin, tannin and prostaglandin (3).

Infectious diseases are the world's leading cause of premature deaths, killing almost 50,000 everyday $(4,5)$. The discovery of effective antimicrobial agent was considered to be one of the greatest contributions to medicine in the $20^{\text {th }}$ century (6). The changing pattern of bacterial aetiology of infections and their altered sensitivitios to antimicrobial agents employed in their treatment call for intensive regular exploration of indigenous plants. This will help us 
identify plants with antimicrobial values that will not only serve as resource for our indigenous pharmaceutical industries but will also serve as an alternative/complementary medicine. Orji and co-workers reported that a particular characteristic of a plant is that. different chemical substances are obtained in members of even the same species in different areas (7).

In view of these, this study was carried out to investigate and evaluate the antimicrobial activities and phytochemical constituents of Sida acuta subspecie acuta leaf and nower combination using different methods of extraction.

\section{MATERIALS AND METHODS}

Plant: Fresh leaves of 'Sida acuta subspecie acuta were collected from Katcha town in Niger state identified and authenticated in herbarium of Biological Sciences department. Ahmadu Bello University, Zaria. Kaduna State, Nigeria.

Extraction: The leaves of Sida acuta subspecie acuta were collected fresh, macerated with mortar and "pestle then dried in sun for about 45 minutes and grounded using mortar and pestle.

Twenty $(20 \mathrm{~g})$ of the powdered leaf was weighed into 4 conical flasks and $100 \mathrm{~m} / \mathrm{s}$ each of hexane, chloroform, methanol and water added to the flasks. The mixtures were thoroughly shaken and allowed to stand for 24 hours. The mixtures were filtrated separately through whatman No. I filter paper into measuring cylinders and concentrated to dryness using water bath and dessicator. The driẹd residue was stored at $4^{\circ} \mathrm{C}$ until ready to use.

Preparation of extract: Serial concentrations: $70,80,20$ and $100 \%$ of the hexane, methanol, chioroform and water extracts were prepared and sterilized through $0.45 \mu \mathrm{m}$ membrane filter paper.

Bacterial isolates: The bacterial isolates of Streptococcus pyogenes, Streptococcus pneumoniae, Klebsiella pneumoniae Escherichia coli, Salmonella typhi. Salmonella typhimurium and Pasteurella multocida were donated by the department of Veterinary Public Health and Animal Production. Usmanu Danfodiyo University Sokoto, Nigeria, but authenticated by chemical and serological tests as described by Cheescbrough (10) although preserved on blood agar slant and stored at $4^{\circ} \mathrm{C}$ until ready to use.

Other materials: include nutrient agar plates (70), isotonic sodium chloride solution. Mueller-Hinton agar, pieces of dried petri dish plates $(70)$. Whatman (No.1) paper, measuring ruler and distilled water.

In vitro test: The isolates of $S$. pyogenes, $S$. pneumoniae, $K$. pneumoniae, $E$ coli, $S$ typhi, $S$ typhimurium and P. multocida were subcultured overnight at $37^{\circ} \mathrm{C}$ on nutrient agar plates, 10 plates per microorganism. The suspension of each bacterial were prepared as described by John et al (11) using isotonic sodium chloride solution.

Dried petidish, 10 per each microorganism of Mueller-llinton agar were flooded with the appropriate suspensions of the bacterial isolates. Sterile $6 \mathrm{~mm}$ diameter absorbent filter papers (punched out from No.I Whatman paper were impregnated with the appropriate concentrations: $700,800.900$ and $1000 \mathrm{mg}$ of the hexane, chloroform. methanol and water extracts and placed on the corresponding inoculated 70 plates ten per microorganism. After the incubation at $37^{\circ} \mathrm{C}$ for 24 hours, all the plates. were observed for zones of growth inhibition and the diameters of these zones measured in millimeter using measuring reler. 
Table 1: Serial concentrations of the hexane extract and their corresponding zones of inhibition.

\begin{tabular}{|c|c|c|c|c|c|c|c|}
\hline \multirow{2}{*}{$\begin{array}{l}\text { Conc. of } \\
\text { hexane extract } \\
\text { (mg) }\end{array}$} & \multicolumn{7}{|c|}{ Diametric zone of inhibition in millimeter ( $\mathrm{mm}$ ) } \\
\hline & S. pneumoniae & P. Multocida & K.pneumoniae & S.pyogenes & S.typhimrium & S.typhi & E. coli \\
\hline 700 & 0 & 0 & $\overline{0}$ & $\overline{0}$ & 0 & 0 & $\overline{0}$ \\
\hline 800 & 0 & $\mathbf{0}$ & 0 & $\mathbf{0}$ & 0 & 0 & 8 \\
\hline 900 & 0 & 10 & 0 & 16 & 0 & 0 & 13 \\
\hline 1000 & 0 & 14 & 0 & 10 & 0 & 0 & 15 \\
\hline Mean; 850 & 0.0 & 6.0 & 0.0 & 6.5 & 0.0 & 0.0 & 9.0 \\
\hline
\end{tabular}

$E$. coli, S. pyogenes and $P$. multocida exhibited zones of inhibition at concentration ranges between $700-1000 \mathrm{mg}$ as there was no zone of inhibition shown by other microorganisms at concentration ranges between $700-1000 \mathrm{mg} . E$. colit $(9.0 \mathrm{~mm})$ has the highest mean followed by $S$. pyogenes $(6.5 \mathrm{~mm})$ and lastly P.multocida $(6.0 \mathrm{~mm})$ see table 1 .

Table 2: Serial concentrations of the chloroform extract and their corresponding diametric zones of inhibition.

\begin{tabular}{|c|c|c|c|c|c|c|c|}
\hline \multirow{2}{*}{$\begin{array}{l}\text { Conc. of } \\
\text { chloroform } \\
\text { extract (mg) }\end{array}$} & \multicolumn{7}{|c|}{ Diametric zone of inhibition in millimeter $(\mathrm{mm})$} \\
\hline & S. pneumoniae & $\begin{array}{l}\text { P. } \\
\text { Multocida }\end{array}$ & K.pneumoniae & S.pyogenes & S.lyphimurium & S.typhi & $\begin{array}{l}\text { E, } \\
\text { coli }\end{array}$ \\
\hline 700 & 0 & 0 & 0 & 0 & 0 & 0 & 0 \\
\hline 800 & 0 & 0 & 0 & 0 & 0 & 0 & $\mathbf{0}$ \\
\hline 900 & 0 & 10 & 0 & 8 & 0 & 0 & 0 \\
\hline 1000 & 0 & 15 & 0 & 12 & 0 & 0 & 16 \\
\hline Mean: 850 & 0.0 & 6.25 & 0.0 & 5.0 & 0.0 & 0.0 & 4.0 \\
\hline
\end{tabular}

E. coli, $S$. pyogenes and $P$. multocida showed zones of inhibition at concentrations between 900 and $1000 \mathrm{mg}$ with $P$. mullocida $(6.25 \mathrm{~mm})$ showing the highest followed by $S$. pyogenes $(5.0 \mathrm{~mm})$ and then $E$. coli $(4.0 \mathrm{~mm})$. But there was no zone of inhibition shown by other microorganisms between concentration ranges $700-1000 \mathrm{mg}$ (table 2 ). 
Table 3: Serial concentrations of the methanol extract and their corresponding zones of inhibition.

\begin{tabular}{|c|c|c|c|c|c|c|c|}
\hline \multirow{2}{*}{$\begin{array}{l}\text { Conc. of } \\
\text { methanol } \\
\text { extract } \\
\text { (mg) }\end{array}$} & \multicolumn{7}{|c|}{ Diametric zone of inhibition in millimeter $(\mathrm{mm})$} \\
\hline & S. pneumoniae & $\begin{array}{l}P . \\
\text { Multocida }\end{array}$ & K.pneumoniae & S.pyogenes & S.typhimurium & S.typhi & $\begin{array}{l}\mathrm{E} \\
\text { coli }\end{array}$ \\
\hline 700 & 0 & 0 & 0 & 0 & 0 & 0 & 0 \\
\hline 800 & $\mathbf{0}$ & 0 & 0 & 0 & 0 & 0 & 8 \\
\hline 900 & 0 & 8 & 0 & 5 & 0 & 0 & 10 \\
\hline 1000 & 0 & 13 & 0 & 9 & 0 & 0 & 13 \\
\hline Mean; 850 & 0.0 & 5.25 & 0.0 & 3.25 & 0.0 & 0.0 & 3.0 \\
\hline
\end{tabular}

$P$. multocida, $S$. pyogenes and $E$. coli showed zones of inhibition between $900-1000 \mathrm{mg}$ concentration with $P$. multocida $(5.25 \mathrm{~mm})$ having the highest mean, then $S$. pyogenes $(3.25 \mathrm{~mm})$ and lastly $E$. coli $(3.0 \mathrm{~mm})$. Though there was no zone of inhibition exhibited by the rest of microorganisms at any concentration (table 3 ).

Table 4: Serial concentrations of the water extract and their corresponding zones of inhibition

\begin{tabular}{|c|c|c|c|c|c|c|c|}
\hline \multirow{2}{*}{$\begin{array}{l}\text { Conc. of } \\
\text { water } \\
\text { extract } \\
\text { (mg) }\end{array}$} & \multicolumn{7}{|c|}{ Diametric zone of inhibition in millimeter ( $\mathrm{mm})$} \\
\hline & S. pneumoniae & $\begin{array}{l}\text { P. } \\
\text { Multocida }\end{array}$ & K.pneumoniae & S.pyogenes & S.typhimurium & S.typhi & $\begin{array}{l}\text { E. } \\
\text { coli }\end{array}$ \\
\hline 700 & 0 & 0 & 0 & 0 & 0 & 0 & 0 \\
\hline 800 & $\mathbf{0}$ & $\theta$ & 0 & 0 & 0 & $\mathbf{0}$ & 0 \\
\hline 900 & $\mathbf{0}$ & 0 & $\mathbf{0}$ & 0 & $\mathbf{0}$ & $\mathbf{0}$ & $\mathbf{0}$ \\
\hline 1000 & 0 & $\mathbf{0}$ & $\mathbf{0}$ & 0 & 6.5 & $\mathbf{0}$ & 6 \\
\hline Mean; 850 & 0.0 & 0.0 & 0.0 & 0.0 & 1.6 & 0.0 & 1.5 \\
\hline
\end{tabular}

S. typhimurium and E. coli exhibited zones of inhibition at $1000 \mathrm{mg}$ concentration with $S$. typhimurium (1.6mm) having higher mean and $E$. coli $(1.5 \mathrm{~mm})$ as there was no zone of inhibition exhibited by the rest of microorganisms at concentration ranges between $700-1000 \mathrm{mg}$ (table 4 ). 
Table 5: Phytochemical analyses of Sida acuta subspecie acuta methanol, hexane, chloroform and aqueous leaf extracts.

\begin{tabular}{|c|c|c|c|c|c|c|}
\hline Extract & Alkaloid & Tannin & Glycoside & Flavonoid & Steroid & Saponin \\
\hline Methanol & $\because$ & + & - & + & - & + \\
\hline Hexane & + & + & - & + & - & + \\
\hline Chloroform & + & + & - & + & - & + \\
\hline Water & - & + & - & + & - & + \\
\hline
\end{tabular}

Phytochemical analyses revealed the uniform presence of saponin, flavonoid and tannin in all the four extracts. Nonetheless, alkaloid was present in hexane and chloroform extracts as it was absent in methanol and aqueous extracts of Sida acuta subspecie acuta, but steroid was absemt in all the four extracts (table 5).

\section{DISCUSSION}

The antibacterial activity exhibited by hexane, chloroform methanol and aqueous leaf extracts of Sida acuta subspecie acuta on E. coli. S. pyogenes, P. multocida and $S$. typhimurium at various concentrations agrees with the report of Orji et al (7) that Nigeria has an interestingly rich.flora because it has varied climatic conditions ranging from the mangrove swamps and rainforest in the south to the Savanna and torn bush regions in the north. The result conlirmed the report of Shahidi Bonjar and Rashidi Farrokhi that natural resources, especially plants and microorganisms are potent candidates for new drugs (12) as Orji et al (7) reported that a particular characteristic of plants is that different chemical substances are obtained in members of even the same species in different areas. Sida acura subspecie acuta may be used to avert the emergence of antimicrobiual resistance. This has not only resulted in increased morbidity and mortality, but also in higher health care cost (13). Infectious diseases are the world's leading cause of premature deaths killing almost 50, 000 people every day and control of such diseases has posed serious problem especially on the developing nations (14). Differences in the zones of inhibition shown by the hexane chloroform and aqueous extracts might be due to differences in the methods of extraction. It was reflected in the result of phytochemical analyses whereby all the four extracts uniformly revealed the presence of saponin. flavonoid and tannin as alkaloid was present in hexane and chlorolorm extracts. Whereas methanol and aqueous extracts did not reveal the presence of alkaloid. This agres with the report of (Gill that Sida acuta subspecie acua contains saponin. tannin and prostaglandin as it also conlirmed absence of steroid and glycoside in all the four extracts(3)

\section{REFERENCES}

I.

Mann. A., Gbate. M. and Umar, A.N. Sida acuta subspecie acuta. Medicinal and Economic Plants of Nupeland, Jube Evans Books \& publication, p 241 (2003).

2. Iwu, M.M. Catalogue of major medicinal plants. Handbook of African Medicinal plants CRC press, Boca Raton Ann, Arbor London, Tokyo, p. 21. (1993).

3. Gill, L. S. Ethnomedicinal uses of Plants in Nigeria. Uni Ben Press Benin City. Nigeria. P, 276 (1992). 

manual for tropical countries Vol. 17 pp carriage and antimicrobial resistance in 203-305 (1985). isolates of Streptococcus pneumonia. and haemophilus influenza type in children under 5 years of age in Botswana. Int. I. inf. Dis. 3(1): 18-25 (1998).

Chambers, H. F. The emerging epidemiology of Staphy lococcus aureus. Emerg. Infect. Dis., 7(2): 178:182 (2001).

Orji, E.C., Ogbuezue, D.C.; Orji. M.U., Evaluation of antimicrobial activities of 13. leaf extracts of Morinda lucida and erythrina senegalensis for medical uses. Int. J. of Gen. and Health. Stud. Vol. I No.I pp, 79-83 (2003). of antifungal activity of extract of iwo Cameroonian Ruffaceac Zanihoxyizm lepricuri guill and Zanthoxylum 